Smith, S. M., McIntosh, W. D., \& Bazzini, D. G. (1999). Are the beautiful good in Hollywood? An investigation of the beauty and goodness stereotype on film. Basic and Applied Social Psychology, 21(1): 69-80. (Mar 1999)

Published by Taylor \& Francis (ISSN: 1532-4834).

\title{
Are the Beautiful Good in Hollywood? An Investigation of the Beauty-and-Goodness Stereotype on Film
}

\author{
Stephen M. Smith, William D. McIntosh, Doris G. Bazzini
}

\begin{abstract}
Physically attractive individuals are often viewed more favorably than unattractive people on dimensions that are weakly related or unrelated to physical looks, such as intelligence, sociability, and morality. Our study investigated the role of U.S. films in this "beauty-andgoodness" stereotype. In Study 1, we established that attractive characters were portrayed more favorably than unattractive characters on multiple dimensions (e.g., intelligence, friendliness) across a random sample from 5 decades of top-grossing films. The link between beauty and positive characteristics was stable across time periods, character sex, and characters' centrality to the plot. Study 2 established that exposure to highly stereotyped films can elicit stronger beauty-and-goodness stereotyping. Participants watching a highly biased film subsequently showed greater favoritism toward an attractive graduate school candidate (compared with ratings of an unattractive candidate) than participants viewing a less biased film.
\end{abstract}


The quality of these films is completely beside the point, as they are only required to loyally express my personal worldview-punish the wicked, reward the attractive, and have as little to do with reality as possible.

—Libby Gelman-Waxner (1997; italics added)

Looks may not be everything, but physical good looks usually work in one's favor. Such is the conclusion of a quarter century's worth of research on physical attractiveness (PA) effects. Do the mass media encourage or reinforce the pervasive stereotypes that link beauty and positive traits?

Much of the work on the beauty-and-goodness stereotype was triggered by the report of K. K. Dion, Berscheid, and Walster (1972), who found that "what is beautiful is good" in the eyes of many observers. In a variety of studies conducted since that time, physical good looks have been found to elicit many favorable reactions. Perhaps not surprisingly, people view physically attractive individuals as more desirable romantic partners (Suman \& Kureshi, 1988). In addition, good-looking people are judged less likely to commit criminal acts (Saladin, Saper, \& Breen, 1988), attractive defendants are more likely to receive lenient verdicts in mock trials (Castellow, Wuensch, \& Moore, 1990), attractive infants are rated more favorably than less attractive ones (Karraker \& Stern, 1990), good-looking children are judged to be more socially and academically capable tban less physically appealing ones (Kenealy, Frude, \& Shaw, 1988), grade school children prefer attractive teachers to unattractive teachers (Hunsberger \& Cavanagb, 1988), and perhaps more alarming, mock jurors recommend harsher punishments for defendants who have raped an attractive woman than those who raped an unattractive woman (Kanekar \& Nazareth, 1988). The bias toward the physically attractive can also help explain why researchers have found in several studies that good-looking people tend to earn higher incomes than unattractive peers (Frieze, Olson, \& Russell, 1991; Roszell, Kennedy, \& Grabb, 1990; Umberson \& Hughes, 1987).

Although some real differences (beyond looks themselves) exist between physically attractive and physically less attractive individuals, these actual differences are few and relatively weak compared to the strength of people's stereotypical beliefs. A meta-analysis of studies of actual correlates of attractiveness by Feingold (1992) indicated "no notable relationships between physical attractiveness and basic personality traits" (p. 333) or between attractiveness 
and character (e.g., manipulativeness). The main characteristics that truly separate attractive and unattractive people were found to be loneliness, social anxiety, popularity witb the opposite sex, and variety of sexual experiences. The evidence suggests quite clearly that the preferential judgments and attributions bestowed on physically attractive individuals are out of concert with actual differences in ability, character, and personality relative to unattractive people.

Nevertheless, a meta-analytic review ofthe PA stereotyping literature showed that even though the magnitude of beauty-and-goodness effects varied considerably among studies, overall researchers found a moderate effect present (Eagly, Ashmore, Makhijani, \& Longo, 1991). The effects of attractiveness were strong for judgments of social competence; moderate for judgments of mental health, social dominance, and intellectual ability; and not significant for judgments of integrity and concem for others.

Even though conceptions of what constitutes PA may be partially determined at birth (Langlois et al., 1987), the beauty-and-goodness stereotype itself is believed to be at least partly learned. But from where is it learned? One possibility is that the stereotype results from direct observation of attractive and unattractive people, in which different characteristics are perceived to covary with attractiveness. However, Feingold's (1992) review renders this explanation implausible; attractive people's actual qualities are not much different than those of less attractive people.

Another possibility is that the stereotype develops through acculturation. Important for our research, the entertainment media has been implicated as a source of the stereotype, primarily by portraying physically attractive characters as "good" and unattractive characters as "bad" (e.g., Aronson, Wilson, \& Akert, 1994). But what is the evidence that the popular media portray an unbalanced view of physically attractive people? As noted by Eagly et al. (1991), "appropriate content analyses of media content are lacking" ( $p$. 112), and hence reviewers of this literature have been forced to fall back on citing a few specific films (most typically, Cinderella) to support the contention that the media play a central role in encouraging the beauty-and-goodness stereotype (e.g., Feldman, 1995).

Our purpose here was to gather evidence bearing on the issue of entertainment media influences on the beauty-andgoodness stereotype. Specifically, we sought to analyze a sample of media from the past 5 decades and assess the extent to which beauty is associated with "goodness" (and positive 
traits in general). We opted to use the film medium for this study. Researchers have estimated that almost two thirds of the adult population sees at least two movies each year and, as recently as 1989, U.S. cinemas drew well in excess of 1 billion customers, for an average of approximately five films viewed per U.S. citizen (Monush, 1996).

We selected a sample of 100 films from 1940 through 1989 , and a team of raters evaluated the PA ofthe main characters and a variety of other attributes (i.e., their goodness, intelligence, friendliness, aggressiveness, romantic activity, socioeconomic status [SES], and outcome). In Study 2, we moved to the laboratory and asked participants to view films that we selected based on their level of beauty-and-goodness stereotyping. We then subjected our participants to a task in which they evaluated an application submitted by either an attractive or an unattractive candidate, anticipating greater bias toward the attractive candidate among participants exposed to a highly stereotyped film.

\section{STUDY 1}

\section{Hypotheses}

Our primary hypothesis in Study 1 was that characters' PA would be significandy associated with some of the positive characteristics assessed. Based on previous findings (Ashmore \& Longo, 1995; Eagly et al., 1991; Feingold, 1992), we anticipated that the relationship would be strongest between attractiveness and measures of social competence, particularly romantic activity, but also for friendliness, and weaker between PA and intelligence or SES, which are found to be moderately associated with looks (e.g., Jackson, Hunter, \& Hodge, 1995; Umberson \& Hughes, 1987); and we expected no PA effects on characters' outcome at film's end (e.g., "lived happily ever after"), goodness, or aggression because morality is generally uncorrelated with PA in the literature (e.g., Eagly et al., 1991).

We also sought to examine trends over time in the link between PA and positive characteristics. Because the beauty bias has been established in the literature since the early 1970s, has public awareness ofthe stereotype led filmmakers to combat it in their films, or has the bias remained stable over time?

We predicted that PA effects would be stronger for female characters than for male characters, and we based this prediction on research suggesting that looks are seen as more important to women's gender roles rather than to 
men's (e.g., Bar-Tal \& Saxe, 1976) and a study of television ads that found that looks and positive outcomes were more commonly linked for women than for men (Downs \& Harrison, 1985). Research on attractiveness and liking has shown that looks are more important to a woman's ability to attract men than to a man's ability to attract women (e.g., Feingold, 1990; Kenrick, Sadalla, Groth, \& Trost, 1990), so we predicted that the difference between PA effects for women and men would be most evident on the measure of romantic activity.

Finally, we expected that central characters would be portrayed more favorably than peripheral characters. Feingold (1992) suggests that leading actors are "not only inordinately attractive, but they also ooze charm and sensuality" (p. 333). Because the central characters are more noticeable, any covariations between PA and goodness among such characters could be particularly influential. Thus we also examined the relationship between PA and goodness across levels of character centrality (central, secondary, and peripheral).

\section{Method}

In Study 1 we attempted to assess the validity of the claim that Hollywood films project a stereotype that favors the physically attractive. To assess this contention, we first needed to identify a representative collection of films. A comprehensive study of all films would have proved too lengthy, so we decided to study a sample of U.S. films beginning with 1940 (relatively few films were produced prior to the 1940s).

\section{Selection of Target Films}

To compile a representative pool of films, we started from the assumption that more popular films (i.e., those that drew the largest audiences) would have a greater influence on the prevalence of people's stereotype and hence were more important to examine than lesser known films. Thus, we obtained lists of the top-grossing movies from each year between 1940 and 1989, counting only a film's revenues at first release. We included the top 20 films from each year in our initial pool; thus we had 1,000 films in the initial pool, 200 for each decade.[1] To arrive at a more manageable number, we randomly chose 100 films from this initial pool. We imposed one constraint on randomness in selecting these films: We required 20 films for each decade. The resulting sample of films is listed in the Appendix and included the following genres: 24\% comedy; 24\% drama; 14\% action-adventure; 
$13 \%$ musical; $6 \%$ suspense; $5 \%$ children-family; $4 \%$ western; and $3 \%$ science fiction-fantasy.

\section{Rating Procedure}

We provided extensive training materials for each of the 11 raters ( 5 men, 6 women), and at least 2 people rated each film. Films were viewed by an average of 3.38 raters, who were instructed to rate all characters identified by name or appear in what the rater considered to be a significant number of scenes. Characters were rated on the following dimensions.

1. Attractiveness. We based ratings of PA on an 11-point scale ranging from 0 (extremely unattractive) to 10 (extremely attractive) and instructed peuticipants to make this rating the first time the character was shown on screen in a reasonably clear, full-faced shot.

2. Aggressiveness. We defined aggressiveness as physical or verbal abuse of other people, and rated it on a scale ranging from 0 (not at all aggressive) to 10 (extremely aggressive).

3. Friendliness. Raters assessed each character's friendliness on a scale ranging from 0 (extremely unfriendly) to 10 (extremely friendly).

A. Goodness. Raters assessed the character's moral virtue on a scale ranging from 0 (extremely immoral) to 10 (extremely moral, saintly).

5. Intelligence. Raters assessed the character's intelligence on a scale ranging from 0 (extremely unintelligent, a moron) to 10 (extremely intelligent, a genius).

6. Outcome. At film's end, participants rated each character's outcome on a scale of 0 (extremely negative; e.g., death) to 10 (extremely positive; e.g., struck it rich and lived happily ever after.)

7. Romantic activity. Participants rated a character's real or implied romantic involvement, sexual involvement, or both on a scale ranging from 0 (totally Inactive) to 10 (extremely active). Due to changing norms and laws, recent films portray this more explicitly. In an attempt to balance this inequity, raters attempted to estimate how much romantic or sexual activity a character was portrayed to be involved in, rather than consider only the amount of time the characters actually engaged in romantic activity, sexual activity, or both.

8. SES. Participants rated SES on a scale ranging from 0 (extremely poor, lower class) to 10 (extremely rich, upper class). 
In addition to these ratings, each rater identified the character's sex and rated the character's role in the film as either central (leading character), secondary (supporting character), or peripheral (appearing in only a few scenes). With the exception of attractiveness ratings, raters could make the ratings at any point during the film. However, in cases where a character's aggressiveness, SES, and so forth, changed during the course of the film, participants often revised ratings for that character on that dimension, and we used the last rating in the analysis. Raters were required to stick with their original attractiveness rating to eliminate the possibility of altering attractiveness ratings after finding out whether a character was good or bad (e.g., a rater might deduct a few attractiveness points after seeing a character engage in evil acts). Whenever two or more raters viewed a film together, we asked that no discussion of the characters or plot of the film occur until all ratings were complete, thereby eliminating opportunities for raters to influence each others' judgments.

Rater reliability. Although we involved several individuals in rating the films, a few raters viewed a disproportionately high number of films. We first sought to establish the reliability of the three raters who were responsible for the majority of the ratings. We assessed their reliability by randomly selecting 15 films from our sample that all three core raters scored. For each of the 134 characters in these films, we analyzed the reliability of these raters for each primary measure using a random effects model. The analysis yielded the following alphas: attractiveness, .96; aggressiveness, .91; friendliness, .86; goodness, ,97; intelligence, .79; outcome, .98; romantic activity, .85; and SES, .94.

We also assessed reliability for a random sample of raters, including both the core raters and the remaining raters. We used 117 character ratings in this analysis in which we again selected 15 films at random and then selected three raters randomly from among those viewing each of these films. Again, reliabilities across raters were well above acceptable levels across all dimensions rated, ranging from a low of .74 (for intelligence) to a high of .94 (for outcome). The reliability for attractiveness ratings was in the middle of this range $(\mathrm{a}=.86)$. From these data, our raters' efforts did not seem to suffer from significant idiosyncratic biases. However, shared biases regarding the covariance between beauty and goodness might have influenced the observed correlations between beauty and the other measured variables. Specifically, the raters may have shared a belief that more attractive people are better people and biased their ratings to produce this relationship (e.g., increasing the ratings of attractiveness for characters portrayed positively). 
To investigate this possibility, we asked a sample of undergraduate volunteers $\left(A^{\wedge}=88\right)$ to rate the attractiveness (on

the same 10-point scale we used earlier) of photos of 41 characters taken from our sample of films. We then averaged and compared these ratings to the ratings of attractiveness our raters assigned. For the subsample of 41 characters, the correlation between the ratings generated by the raters and the ratings provided by the students was $r=.575, p<.001$. This correlation was undermined by the fact that our undergraduates were surprisingly prone to giving same-sex characters attractiveness scores of 0 , whereas the raters in our study seldom gave ratings of 0 (our guess is that many of the undergraduates believed anything other than a 0 rating of a same-sex person's attractiveness indicated homosexual inclinations). Eliminating the zeroes from the student sample elevated the correlation between ratings to $r=.761$. Most important, however, the correlation between beauty and goodness was .258 using our ratings of attractiveness and goodness, and ,388 using the students' ratings of attractiveness and our ratings of goodness. So, if our ratings were biased at all, they appear to be biased against the beauty-and-goodness stereotype, $f(38)=3.76, p<.01$.

We implemented another protective measure prior to the beginning of data collection. Each of our core raters submitted a written summary of their expectations of what significant results would be found before viewing any of the films in the study. Content analysis of these lists (available from Stephen Smith) indicated only one consistent expectancy across raters: They expected the relation between beauty and goodness to be strongest in early decades and weakest in the 1980s. As we discuss later, our results suggested nonsignificant variations across decades. Taken together, the fact that interrater reliabilities were quite high, that the attractiveness ratings produced by a naive sample of students yielded nominally higher correlations with goodness than our own ratings, and that raters' expectancies of what we would find were completely idiosyncratic (save for one shared expectancy that clearly did not produce the expected finding), argue quite consistently for the reliability of our results.

\section{Results and Discussion}

\section{Test for General PA Bias}

Table 1 presents means and standard deviations for all measured variables, and Table 2 shows intercorrelations for all measured variables. Because the characters appeared with other characters who were also being rated, analyzing all 833 rated characters would violate the assumption of independence. 
Hence, we randomly selected one character from each

film for inclusion in the regression analyses. We performed

separate regressions using aggressiveness, friendliness, goodness, intelligence, outcome, romantic activity, and SES as criterion variables. Predictor variables in these equations included beauty, character sex (coded $1=$ female, $2=$ male), character centrality (coded $1=$ central, 2 - secondary, $3=$ peripheral), and decade of film ( $1=1940 \mathrm{~s}, 2=1950$ s, etc. $)$. We also entered cross-product interaction terms for Beauty $x$ Sex, Beauty $x$ Character Centrality, and Beauty $x$ Decade. We used simultaneous solutions due to the high number of tests conducted. The results of these regression analyses appear in Table 3.[2]

TABLE 1

Means and Standard Deviations of Measured Variables

\begin{tabular}{lcc}
\hline Variable & $M$ & $S D$ \\
\hline Aggressiveness & 2.08 & 2.60 \\
Beauty & 5.83 & 1.73 \\
Friendliness & 5.49 & 1.84 \\
Goodness & 5.80 & 2.14 \\
Intelligence & 5.67 & 1.29 \\
Outcome & 5.16 & 2.91 \\
Romantic activity & 1.38 & 2.09 \\
Socioeconomic status & 5.80 & 1.82 \\
\hline
\end{tabular}

TABLE 2

Intercorrelations Among Measured Variables

\begin{tabular}{lccccccrr}
\hline & 1 & 2 & 3 & 4 & 5 & 6 & 7 & 8 \\
\hline 1. Aggressiveness & 1.00 & -.016 & -.342 & -.428 & -.083 & -.243 & .289 & -.093 \\
2. Beauty & & 1.00 & .353 & .357 & .295 & .257 & -.233 & .103 \\
3. Friendliness & & & 1.00 & .735 & .236 & .379 & -.024 & -.145 \\
4. Goodness & & & & 1.00 & .363 & .471 & -.169 & -.024 \\
5. Intelligence & & & & 1.00 & .131 & .049 & .401 \\
6. Outcome & & & & & 1.00 & -.117 & .059 \\
7. Romantic activity & & & & & & & 1.00 & -.043 \\
8. Socioeconomic status & & & & & & & & \\
\hline
\end{tabular}

Note. All correlations exceeding .07 in this table are statistically significant $(p<.05)$. 
TABLE 3

Regression Analyses Using Beauty, Decade, Sex, and Character Importance as Predictors

\begin{tabular}{|c|c|c|c|c|c|}
\hline Criterion and Predictor & $B$ & $S E$ of $B$ & $t$ & $p$ & $s r^{2}$ \\
\hline \multicolumn{6}{|l|}{ Aggressiveness } \\
\hline Beauty & -.395 & .247 & -1.60 & .111 & .024 \\
\hline Decade & .111 & .219 & .506 & .613 & .002 \\
\hline Sex & .262 & .688 & .381 & .703 & .001 \\
\hline Character importance & -.555 & .399 & -1.39 & .165 & .018 \\
\hline Beauty $\times$ Decade & .006 & .036 & .153 & .878 & $<.001$ \\
\hline Beauty $\times$ Sex & .220 & .108 & 2.05 & .041 & .040 \\
\hline Beauty $\times$ Character Importance & -.006 & .064 & -1.01 & .919 & $<.001$ \\
\hline $\begin{array}{l}\text { Constant } \\
\text { Total }\end{array}$ & 2.612 & 1.669 & 1.57 & .118 & .085 \\
\hline \multicolumn{6}{|l|}{ Friendliness } \\
\hline Beauty & .034 & .172 & .199 & .843 & $<.001$ \\
\hline Decade & -.21 & 4.153 & -1.39 & .164 & .018 \\
\hline Sex & -.703 & .479 & -1.47 & .143 & .020 \\
\hline Character importance & -.596 & .279 & -2.14 & .033 & .042 \\
\hline Beauty $\times$ Decade & .020 & .025 & .815 & .415 & .006 \\
\hline Beauty $\times$ Sex & .067 & .075 & .891 & .373 & .007 \\
\hline Beauty $\times$ Character Importance & .051 & .044 & 1.15 & .250 & .012 \\
\hline Constant & 6.740 & 1.164 & 5.79 & $<.001$ & \\
\hline Total & & & & & .105 \\
\hline \multicolumn{6}{|l|}{ Goodness } \\
\hline Beauty & .372 & .198 & 1.88 & .061 & .032 \\
\hline Decade & -.312 & .176 & -1.77 & .076 & .028 \\
\hline Sex & -.905 & .551 & -1.64 & .101 & .024 \\
\hline Character importance & .404 & .320 & 1.26 & .207 & .014 \\
\hline Beauty $\times$ Decade & .031 & .029 & 1.09 & .277 & .011 \\
\hline Beauty $\times$ Sex & .083 & .086 & .958 & .338 & .008 \\
\hline Beauty $\times$ Character Importance & -.132 & .051 & -2.59 & .009 & .061 \\
\hline Constant & 5.420 & 1.336 & 4.06 & $<.001$ & \\
\hline Total & & & & & .178 \\
\hline \multicolumn{6}{|l|}{ Intelligence } \\
\hline Beauty & .187 & .121 & 1.55 & .123 & .022 \\
\hline Decade & -.325 & .107 & -3.03 & .002 & .085 \\
\hline Sex & .277 & .336 & .824 & .410 & .006 \\
\hline Character importance & .109 & .195 & .556 & .578 & .003 \\
\hline Beauty $\times$ Decade & .035 & .017 & 2.01 & .044 & .038 \\
\hline Beauty $\times$ Sex & .013 & .052 & .242 & .809 & $<.001$ \\
\hline Beauty $\times$ Character Importance & -.059 & .031 & -1.89 & .059 & .033 \\
\hline Constant & 4.792 & .815 & 5.88 & $<.001$ & \\
\hline \multirow{2}{*}{\multicolumn{6}{|c|}{ Outcome }} \\
\hline & & & & & \\
\hline Beauty & .582 & .275 & 2.12 & .034 & .042 \\
\hline Decade & -.053 & .244 & -.217 & .828 & $<.001$ \\
\hline Sex & -.107 & .763 & -.140 & .889 & $<.001$ \\
\hline Character importance & .320 & .443 & .722 & .470 & .005 \\
\hline Beauty $\times$ Decade & .049 & .040 & 1.23 & .220 & .014 \\
\hline Beauty $\times$ Sex & -.053 & .119 & -.445 & .657 & .002 \\
\hline Beauty $\times$ Character Importance & -.192 & .071 & -2.71 & .007 & .069 \\
\hline Constant & 3.308 & 1.852 & 1.79 & .074 & \\
\hline Total & & & & & .133 \\
\hline \multicolumn{6}{|l|}{ Romantic activity } \\
\hline Beauty & .824 & .179 & 4.60 & $<.001$ & .165 \\
\hline Decade & .173 & .159 & 1.09 & .278 & .009 \\
\hline Sex & -.403 & .498 & -.808 & .419 & .005 \\
\hline Character importance & .471 & .290 & 1.63 & .104 & .021 \\
\hline Beauty $\times$ Decade & -.015 & .026 & -.593 & .553 & .003 \\
\hline Beauty $\times$ Sex & -.021 & .078 & -.265 & .791 & $<.001$ \\
\hline Beauty $\times$ Character Importance & -.197 & .046 & -4.26 & $<.001$ & .141 \\
\hline Constant & -1.517 & 1.209 & -1.26 & .210 & \\
\hline Total & & & & & .345 \\
\hline \multicolumn{6}{|l|}{ Socioeconomic status } \\
\hline Beauty & .202 & .182 & 1.11 & .268 & .010 \\
\hline Decade & -.270 & .162 & -1.67 & .096 & .029 \\
\hline Sex & .709 & .506 & 1.40 & .162 & .021 \\
\hline Character importance & -.199 & .295 & -.675 & .500 & .005 \\
\hline Beauty $\times$ Decade & .014 & .027 & .541 & .589 & .003 \\
\hline Beauty $\times$ Sex & -.126 & .079 & -1.58 & .114 & .026 \\
\hline Beauty $\times$ Character Importance & .034 & .047 & .731 & .465 & .006 \\
\hline Constant & 5.209 & 1.231 & 4.23 & $<.001$ & \\
\hline Total & & & & & .101 \\
\hline
\end{tabular}


We anticipated that beauty would be most reliably associated with heightened levels of romantic activity and friendliness. Although beauty was indeed strongly related to levels of romantic activity, $B=.824, p<.01$, it was not a significant predictor of friendliness, $B=.034, n s$. We predicted a moderate level of association between beauty and both intelligence and SES and no association between beauty and either outcome, goodness, or aggression. However, beauty was only weakly associated with intelligence $(6=.187, / 7<.13)$ and essentially unrelated to SES (B - .192, $p>.25$ ). Beauty was a weak, unreliable predictor of aggression, $B--.395, p<.12$, with more attractive characters displaying slightly lower levels of aggression. However, beauty was more reliably related to both goodness $\{B=.372, p<.07$ ) and outcome ( $\mathrm{S}-.582, p$ $<.05)$. Despite previous research indicating no clear evidence that attractive people actually have better life outcomes (i.e., "living happily ever after"; Feingold, 1992) than unattractive people, this was certainly the case in many of our films. To summarize, our guesses were less than perfect regarding which characteristics would be most strongly related to characters' PA, but we found a clear tendency for attractive characters to be portrayed more favorably overall. Variation by decade. To test for variability of PA effects across decades, we examined the Beauty $x$ Decade predictor terms for each analysis. As noted earlier, several raters expected to find reduced stereotyping in recent films relative to older films, but this was clearly not the case. The interaction between beauty and decade fell far short of significance $\{p s>.20$ ) for everything except intelligence, for which a significant Beauty $x$ Decade interaction emerged, $B=.035, p<$ .05 . The positive regression coefficient indicated that beauty was actually a better predictor of intelligence in more recent movies than in earlier ones (see Table 4).

TABLE 4

Beauty and Intelligence Regressions by Decade

\begin{tabular}{lcccc}
\hline Decade & $\boldsymbol{B}$ & SE of $\boldsymbol{B}$ & $\boldsymbol{t}$ & $\boldsymbol{p}$ \\
\hline $1940 \mathrm{~s}$ & .237 & .134 & 1.76 & .09 \\
$1950 \mathrm{~s}$ & .027 & .096 & 2.84 & .78 \\
$1960 \mathrm{~s}$ & .252 & .164 & 1.54 & .14 \\
$1970 \mathrm{~s}$ & .402 & .166 & 2.42 & .03 \\
$1980 \mathrm{~s}$ & .378 & .124 & 3.04 & .01 \\
\hline
\end{tabular}

Although not particularly germane to our hypotheses, we found a main effect of decade on ratings of intelligence, $B=$ $-.325, p<.001$. This result suggested that characters tended 
to be portrayed as less intelligent in more recent films than in older movies.

Variation by character sex. We expected beauty to predict more reliably positive qualities in female rather than in male characters. Contrary to our hypotheses, large sex differences in the strength of the PA bias did not emerge. The Beauty $x$ Sex interaction term approached significance only for aggression, $B=.220, p<.05$. As seen in Table 5 , PA was a modest, positive correlate of aggressive behavior for male characters, although beciring a slight, negative relationship to aggression in female characters.

TABLE 5

Beauty and Aggression Regressions by Character Sex

\begin{tabular}{lcccc}
\hline Sex & $B$ & $S E$ of $B$ & $t$ & $p$ \\
\hline Women & -.119 & .169 & -.70 & .49 \\
Men & .237 & .193 & 1.23 & .22 \\
\hline
\end{tabular}

Variation by character importance. We performed a final set of analyses to test the hypothesis that central characters would be portrayed more favorably than less important characters. Central characters in our sample were indeed rated as more attractive $(A /=6.88)$ than secondary $(M=5.50)$ characters, $t\{64)=3.83, p<.001$, or peripheral $\{M=5.25$ ) characters, $t\{62)-5.22, p<.001$. The latter two groups of characters did not differ in PA, $t\{54)=1.61$, ns. Regression analyses indicated that central characters also received more favorable ratings than less important characters on friendliness, $B=-.596, p<.05$, but no other significant effects emerged for character importance.

We also looked at the Beauty $x$ Centrality interaction terms in the regression analyses to see if the beauty-and-goodness relation varied by character importance. Surprisingly, the relation between the Beauty $x$ Centrality interaction and several variables (friendliness, goodness, intelligence, and outcome) was significant (Bs = -.051, $-.132,-.059$, and -.192 , respectively; all $p s<.05$ ). The pattern of these interactions (see Table 6) suggested that beauty-and-goodness stereotyping was most pronounced for central characters with the primary exception being for outcome, for which we found no relation between beauty and goodness for central characters. This is perhaps due to the fact that central characters seldom die in the film whereas less important characters are more expendable. 
TABLE 6

Beauty Regressions Within Levels of Character Centrality on Friendliness, Goodness, Intelligence, and Outcome

\begin{tabular}{lcccc}
\hline Centrality & $B$ & $S E$ of $B$ & $t$ & $p$ \\
\hline Friendliness & & & & \\
$\quad$ Central & .453 & .159 & 2.39 & .03 \\
Secondary & .292 & .244 & 1.19 & .24 \\
$\quad$ Peripheral & .220 & .189 & 1.39 & .17 \\
Goodness & & & & \\
Central & .397 & .179 & 2.21 & .04 \\
Secondary & .346 & .295 & 1.17 & .25 \\
$\quad$ Peripheral & .307 & .223 & 1.38 & .18 \\
Intelligence & & & & \\
Central & .429 & .107 & 4.03 & .01 \\
Secondary & .353 & .155 & 2.28 & .04 \\
$\quad$ Peripheral &. .069 & .115 & -0.60 & .56 \\
Outcome & & & & \\
$\quad$ Central & -.246 & .302 & -.82 & .42 \\
Secondary & .419 & .366 & 1.14 & .26 \\
Peripheral & .308 & .273 & 1.13 & .27 \\
\hline
\end{tabular}

\section{CONCLUSIONS}

The results of our investigation indicate quite clearly that Hollywood filmmakers have been portraying physically attractive individuals more favorably than their less attractive film counterparts in terms of their moral goodness, romantic activity, and life outcomes. This bias was reliably present throughout the period studied (1940-1989), was apparent for both male and female characters, and was most pronounced for central characters.

Left unanswered in our data, however, is another important question. Although the movies may indeed project a stereotyped view of good-looking people, is the public influenced by these stereotyped portrayals? To be sure, much evidence suggests that the messages of the mass media are widely accepted in the population. For example, research has indicated that televised aggression increases many viewers' own aggressiveness (e.g., Bandura, Ross, \& Ross, 1963; Berkowitz \& Geen, 1966). The entire advertising industry is founded on the assumption that public attitudes can be altered by exposure to media messages, and research suggests that repeated exposure to ads does indeed alter attitudes (e.g., Schumann, Petty, \& Clemons, 1990). Mass media appeals can increase prosocial behavior as well. For example, when townhouse and apartment dwellers were shown videotaped messages about energy-saving behaviors, they significantly 
altered their energy-related habits (Winett et al., 1982). Most directly relevant to our work, studies have shown that media portrayals of gender stereotypes directly impact the stereotypes of viewers (e.g., Geis, Brown, Jennings, \& Porter, 1984).

Nevertheless, evidence regarding the ability of the media to affect or create stereotypes is scant. The mere presence of stereotypical portrayals in the media tells us little about their influence. For example, studies suggest that changes in stereotypical depictions of Black people on prime-time television have coincided with apparent changes in society's views of Black people (Weigel, Kim, \& Frost, 1995). But does this suggest that changes in media portrayals have produced changes in public attitudes? Does it suggest that changes in public attitudes have produced changes in the programming choices of television executives? Or does it suggest that other variables are responsible for both changes? In the absence of controlled studies, we cannot confidently draw causal conclusions. Conducting such a study was the objective of our second investigation.

\section{STUDY 2}

Our second study experimentally examined the hypothesis that exposure to films with stereotypical depictions of attractive people as good can subsequently influence the stereotypes of viewers regarding the relationship between beauty and goodness. We selected four films from Study 1 for inclusion in our laboratory follow-up.

\section{Method}

Participants and design. Fifty-seven female and 26 male undergraduate students in lower division psychology classes participated for extra credit, and we randomly assigned them to film conditions. Approximately one half watched a film that data from Study 1 indicated to be high in beauty-and-goodness stereotyping (specifically, correlations between the PA and the goodness ofthe film's characters exceeded .75); remaining participants viewed a film with low levels of beauty stereotyping (with correlations between PA and goodness of less than .10). Subsequent to viewing the full-length film, participants completed an "unrelated" second experiment in which they rated the applications of two fictitious graduate school candidates, one of whom was physically attractive and one of whom was physically unattractive (photos were attached to the applications). The photos had been shown to reliably elicit divergent attractiveness ratings 
in a previous investigation (Petty \& Cacioppo, 1981). Both applicants were of the same sex with target sex manipulated randomly between participants. The resulting design was a mixed factorial including the following variables: film type (high- vs. low-beauty stereotyping; between-participants), participant sex (male vs. female; between-participants), target sex (male vs. female; between-participants), and target attractiveness (attractive vs. unattractive; within-participant).

Procedures. We informed participants that they were taking part in two separate experiments; the first involved pilot testing a movie for use in future research and the second involved checking the reliability of graduate school admissions decisions. After obtaining informed consent, the experimenter proceeded to show participants one of four films. The films, selected from our initial pool of 100 on the basis of very high or very low beauty-and-goodness correlations according to our ratings, were Pride ofthe Yankees (high bias, drama). Road to Utopia (high bias, musical). Up the Down Staircase (low bias, drama), and Rhapsody in Blue (low bias, musical).[3]

After viewing the film, participants provided several ratings that supported the cover story but were otherwise inconsequential for our study. We then asked them to close the folder containing the film ratings and gave them a second folder containing four sheets. We told them that a nearby university had asked for some assistance in checking the reliability of their graduate school admissions decisions and wanted to have a set of applications rated by novices with no knowledge of the candidates and no special expertise in the planned area of study (psychology).

The folders contained two single-page resumes with a black-and-white photograph of the applicant in the upper right corner. The qualifications ofthe candidates were essentially equivalent, but were cosmetically varied to reduce suspicion (e.g., different fonts, college affiliations, and club memberships). Each participant judged two applications that were matched on sex and approximate qualifications but whose photographs were manipulated such that one was particularly attractive and the second was particularly unattractive (the main deviation from standardization of the applications was that the unattractive candidate was always identified as having a slightly higher grade point average than the attractive applicant). The attractiveness manipulation was validated in previous research (Haugtvedt, Petty, \& Cacioppo, 1992).

We asked participants to take their time reviewing the resumes and then rate the applicants separately on a 10-point 
scale ranging from 1 (not at all qualified) to 10 (extremely well qualified). After completing the evaluations, we probed participants for suspicion, debriefed them, and thanked them for their participation.

\section{Results}

The primary objective of the study was to see if exposure to beauty-biased films would increase the extent to which people favored attractive candidates. Thus the key prediction was an interaction between film type (high vs. low bias) and candidate's attractiveness. The dependent variable was the rating assigned to each candidate on a 10-point scale.

Overall ratings of candidates differing in attractiveness. We performed a mixed 2 (Film Type; betweenparticipants) $\times 2$ (Participant Sex) $\times 2$ (Target Sex) $\times$ 2 (Candidate's Attractiveness; within-participant) analysis of variance on the ratings of candidate's qualifications for graduate school. Five participants failed to complete this item and were dropped from the analysis. The analysis revealed a significant main effect of $P A, F(I, 69)=47.49, p$ $<.001$, that mirrored past findings. Physically attractive candidates received more favorable ratings $(M=7.79)$ than did unattractive candidates $(M=6.49)$.

TABLE 7

Ratings of Attractive Versus Unattractive Applicants by Participants Having Viewed Either a High-Stereotyped or Low-Stereotyped Film

\begin{tabular}{|c|c|c|c|c|}
\hline \multirow[b]{3}{*}{ Beauty Stereotyping } & \multicolumn{4}{|c|}{ Attractiveness of Applicant } \\
\hline & \multicolumn{2}{|c|}{ Attractive } & \multicolumn{2}{|c|}{ Unattractive } \\
\hline & $M$ & $S D$ & $M$ & $S D$ \\
\hline $\mathrm{High}^{*}$ & 7.91 & 1.00 & 6.21 & 1.52 \\
\hline Low & 7.57 & 1.29 & 6.86 & 1.70 \\
\hline
\end{tabular}

However, this effect was qualified by a significant interaction, $F(1,69)=6.41, l ;<.05$. (See Table 7 for means.) Simple effects tests indicated that the favoritism for the more attractive candidate was particularly strong among participants exposed to a highly stereotyped film, $\mathrm{r}(41)=7.84, p<$ .001 , although those exposed to a low-bias film also favored the attractive candidate, $r(33)=2.92, p<.05$. 
Thus, our Study 2 results repeated past findings in that our participants rated attractive people more favorably than unattractive people. Importantly, however, we went beyond the past literature by directly demonstrating the influence of a situational variable-exposure to stereotyped films-on the magnitude of the tendency to favor the physically attractive. This effect was the consequence of exposure to only one film.

\section{GENERAL DISCUSSION}

The PA literature has clearly demonstrated that a prevalent judgmental bias favoring physically attractive people exists; they are viewed as more sociable, more intelligent, better adjusted, and more desirable as romantic partners. Indeed, Hatfield and Sprecher (1986) concluded that physically attractive people are believed to "possess almost all the virtues known to humankind" (p. xix). Although the origins of this bias are not clear, most scholars have either directly or indirectly accused the entertainment media of encouraging or maintaining the "what-is-beautiful-is-good" stereotype (e.g., Aronson et al., 1994). However, this criticism has lacked any scientific support beyond the mere citation of a few examples of films that seem to project the beauty-and-goodness stereotype. We could cite no systematic study of a representative sample of films because none existed. In addition, even if a systematic study had existed, no direct evidence could be cited to support the claim that exposure to attractiveness stereotyped films can lead to actual changes in behavior on the part of viewers. These data ameliorate both of these problems in the literature.

We found, in a representative sample of films across 5 decades, that PA was significantly associated with goodness, romantic activity, and life outcomes. Furthermore, we found that these relationships were consistent across decades. We also discovered that the tendency for physically attractive characters to be portrayed more positively was stronger for central (leading) characters than for lesser characters and that the extent of beauty stereotyping was essentially the same for male characters as for female characters.

A second study supported the validity of a causal path from viewing PA biased films to strengthened stereotypes in favor of attractive people. Participants who viewed highly biased films were more prone to favor a physically attractive applicant in a bogus admissions decision task.

Beyond tying up important loose ends in the PA literature, our research testifies to the power of mass media in influencing 
human attitudes and judgments. When commentators express concern over negative effects of the mass media, they are generally referring to the infiuence of long-term exposure on attitudes and behavior (e.g., Myers, 1996). Our data suggest that such concern is indeed warranted with respect to media promotion ofthe beauty-and-goodness stereotype; we were able to document strong evidence that films tend to portray good-looking characters as good and found evidence of increased beauty stereotyping effects based on a single exposure to a beauty stereotyped film. Given this finding, expecting that repeated exposure would have more powerful-and for some, deleterious-effects seems plausible (e.g., Gerbner, Gross, Morgan, \& Signorielli, 1986).

On a more optimistic note, evidence suggests that media infiuences on stereotypes can work both ways. Researchers have found that portraying women in positions of authority over men reverses the tendency for men to be viewed as more competent than women (Geis, Deitz, Brofee, \& Fennimore, 1992). However, optimism regarding the chances that filmmakers will try and "undo the damage" assumes that these manufacturers of popular media believe they are at least partially responsible for public beliefs and stereotypes. This assumption may not be particularly valid. Consider the following quote from director Stanley Kubrick (1972, as reported in Karney, 1995): " . . . the idea that people can be corrupted by a film is, I think, completely wrong" (p. 10).

Our research studied PA in a global sense, but recent work indicates that beauty is multidimensional and that significant differences exist among the different dimensions. For example, Ashmore, Solomon, and Longo (1996) delineated Trendiness, Cuteness, and Sexiness as separate factors sharing a relationship with ratings of PA. Quite possibly, these separate factors of PA could be differentially responsible for the beauty bias evident in the films we studied, but we can ascertain this only through further research.

Determining what the 1990 s look like in terms ofthe portrayal of physically attractive characters would also be informative. Perhaps we have made progress toward reversing the unfavorable trend apparent in the 50 years of film we sampled. But as was the case for films in general prior to our investigation, our own impressions are all we have to go on to gauge the level of beauty stereotyping in films ofthe 1990s. 


\section{NOTES}

1. We rejected two movies that were selected because the main characters were animated and meaningful attractiveness ratings could not be made.

2. We also analyzed all 833 characters with only minor discrepancies compared to the $\mathrm{Af}=100$ analyses. For example, the interaction between beauty and decade on characters' outcomes was significant in the $W=833$ analysis ( $p$ $<.05)$ but failed to approach significance in the $\left.A^{\wedge}=I C X\right)$ analysis $(p=.22)$.

3. The correlations between beauty and goodness for the films used in Study 2 were: Pride ofthe Yankees, $r=.88$; Road to Utopia, $r=.78$; Up the Down Staircase, $r=-.10$; and Rhapsody in Blue, $r=.03$.

\section{ACKNOWLEDGMENTS}

For their comments, we thank Richard Ashmore, Diane Berry, Alice Eagly, Bill Graziano, Peter McDonald, Michael Strube, and an anonymous reviewer. We also thank Colin Cruthers, Debra Sabia, Jennifer Lund Smith, and Saul Zalesch for their help in the often tedious process of rating films, and Joshua Saint and Gregory Smith for their help in the always tedious process of entering data. 


\section{REFERENCES}

Aronson, E., Wilson, T. D., \& Akert, R. M. (1994). Social psychology: The heart and the mind. New York: HarperCollins.

Ashmore, R. D., \& Longo, L. C. (1995). Accuracy of stereotypes: What research on physical attractiveness can teach us. In Y. T. Lee, L. J. Jussim, \& C. R. McCauley (Eds.), Stereotype accuracy: Toward appreciating group differences (pp. 63-86). Washington, DC: American Psychological Association.

Ashmore, R. D., Solomon, M. R., \& Longo, L. C. (1996). Thinking about fashion models' looks: A multidimensional approach to the structure of perceived physical attractiveness. Personality arul Social Psychology Bulletin, 22, 1083-1104.

Bandura, A., Ross, D., \& Ross, S. A. (1963). Imitation of film-mediated a.ggTessiwemodels. JournalofAbnormalandSocialPsychology, 66, 3-11.

Bar-Tal, D., \& Saxe, L. (1976). Physical attractiveness and its relationship to sex-role stereotyping. Sex Roles, 2, 123-133.

Berkowitz, L., \& Geen, R. G. (1966). Film violence and the cue properties of available targets. Journal of Personality and Social Psychology, 3, 525-530.

Castellow, W. A., Wuensch, K. L., \& Moore, C. H. (1990). Effects of physical attractiveness of the plaintiff and defendant in sexual harassment judgments. Journal of Social Behavior and Personality, 5, 547-562.

Dion, K. K., Berscheid, E., \& Walster, E. (1972). What is beautiful is good. Journal of Personality and Social Psychology, 24, 285-290.

Downs, A. C, \& Harrison, S. K. (1985). Embarrassing age spots or just plain ugly? Physical attractiveness stereotyping as an instrument of sexism on American television commercials. Sex Roles, 13, 9-19.

Eagly, A. H., Ashmore, R. D., Makhijani, M. G., \& Longo, L. C. (1991). What is beautiful is good, but...: A meta-analytic review of research on the physical attractiveness stereotype. Psychological Bulletin, 110, 109-128.

Feingold, A. (1990). Gender differences in effects of physical attractiveness on romantic attraction: A comparison across five research paradigms. Journal of Personality and Social Psychology, 59, 981-993.

Feingold, A. (1992). Good-looking people are not what we think. Psychological Bulletin, /77, 304-341.

Feldman, R. S. (1995). Social psychology. Englewood Cliffs, NJ: Prentice Hall. 
Frieze, I. H., Olson, J. E., \& Russell, J. (1991). Attractiveness and income for men and women in management. Journal of Applied Social Psychology, 21, 1039-1057.

Geis, F. L. (1993). Self-fulfilling prophecies: A social psychological view of gender. In A. Beall \& R. J. Stemberg (Eds)., The psychology of gender (pp. 9-54). New York: Guilford.

Geis, F. L., Brown, V., Jennings, J., \& Porter, N. (1984). T.V. commereials as achievement scripts for women. Sex Roles, 10, 513-525.

Geis, F. L., Deitz, B. L., Brofee, E., \& Fennimore, E. (1992). How to succeed in business without really trying: Same-sex authority models. Unpublished manuscript. University of Delaware, Newark.

Gelman-Waxner, L. (1997, August). Premiere, p. 46.

Gerbner, G., Gross, L., Morgan, M., \& Signorielli, N. (1986). Living with television: The dynamics of the cultivation process. In J. Bryant \& D. Zillman (Eds.), Perspectives on media effects (pp. 17-40). Hillsdale, NJ: Lawrence Erlbaum Associates, Inc.

Hatfield, E., \& Sprecher, S. (1986). Mirror, mirror: The importance of looks in everyday life. Albany: State University of New York Press.

Haugtvedt, C. P., Petty, R. E., \& Cacioppo, J. T. (1992). Need for cognition and advertising: Understanding the role of personality variables in consumer behavior. yoMrna/o/CoayHmer/'fyc/io/ogy, I, 239-260.

Hunsberger, B., \& Cavanagh, B. (1988). Physical attractiveness and children's expectations of potential teachers. Psychology in the Schools, 25, 70-74.

Jackson, L. A., Hunter, J. E., \& Hodge, C. N. (1995). Physical attractiveness and intellectual competence: A meta-analytic review. Social Psychology Quarterly, 58, 108-122.

Kanekar, S., \& Nazareth, A. M. (1988). Attributed rape victim's fault as a function of her attractiveness, physical hurt, and emotional disturbance. Social Behaviour, 3, 37-40.

Kamey, R. (Ed.). (1995). Chronicle of the cinema. New York: Dorling Kindersley.

Karraker, K. H., \& Stem, M. (1990). Infant physical attractiveness and facial expression: Effects on adult perceptions. Basic and Applied Social Psychology, 11, 371-385. 
Kenealy, P., Frude, N., \& Shaw, W. (1988). Influence of children's physical attractiveness on teacher expectations. Journal of Social Psychology, $128,373-383$.

Kenrick, D. T., Sadalla, E. K., Groth, G., \& Trost, M. R. (1990). Evolution, traits, and the stages of human courtship: Qualifying the parental investment model. Journal of Personality, 58, 97-117.

Langlois, J. H., Roggman, L. A., Casey, R. J., Ritter, J. M., Rieser-Danner, L. A., \& Jenkins, V. Y. (1987). Infant preferences for attractive faces: Rudiments of a stereotype? Journal of Personality and Social Psychology, 23, 363-369.

Monush, B. (Ed.). (1996). Motion picture almanac. New York: Quigley. Myers, D. G. (1996). Social psychology. New York: McGraw-Hill.

Petty, R. E., \& Cacioppo, J. T. (1981). Issue involvement as a moderator of the effects on attitude of advertising content and context. Advances in Consumer Research, 8, 20-24.

Roszell, P., Kennedy, D., \& Grabb, E. (1990). Physical attractiveness and income attainmentamongCanadians.yourna/o/Pryc/io/ogy, 123,547-559.

Saladin, M., Saper, Z., \& Breen, L. (1988). Pereeived attractiveness and attributions of criminality: What is beautiful is not criminal. Canadian Journal of Criminology, 30, 251-259.

Schumann, D. W., Petty, R. E., \& demons, D. S. (1990). Predicting the effectiveness of different strategies of advertising variation: A test of the repetitionvariation hypotheses./o«nia/o/Con.rumer/?eiearc/i, 17, 192-202.

Suman, H. C, \& Kureshi, A. (1988). Interpersonal attraction as a function of physical attractiveness, personality similarity-dissimilarity, and reciprocity. Psychologia, 31, 234-238.

Umberson, D., \& Hughes, M. (1987). The impact of physical attractiveness on achievement and psychological well-being. Social Psychology Quarterly, 50, 227-236.

Weigel, R. H., Kim, E. L., \& Frost, J. L. (1995). Race relations on prime time television reconsidered: Patterns of continuity and change. Journal of Applied Social Psychology, 25, 223-236.

Winett, R. A., Hatcher, J. W., Fort, T. R., Leckliter, I. N., Love, S. Q., Riley, A. W., \& Fishback, J. F. (1982). The effects of videotape modeling and daily feedback on residential electricity conservation, home temperature and humidity, perceived comfort, and clothing worn: Winter and summer. Journal of Applied Behavior Analysis, 15, 381-402. 


\section{APPENDIX}

\section{LIST OF FILMS VIEWED IN THIS STUDY}

1940

My Favorite Wife

All This and Heaven Too

1941

The Ziegfield Girl

That Hamilton Woman

Hold That Ghost

1942

Pride of the Yankees

My Favorite Blonde

1943

Madame Curie

1944

Dragon Seed

1945

Spellbound

Road to Utopia

Rhapsody in Blue

Caesar and Cleopatra

A Tree Grows in Brooklyn

1946

It's a Wonderful Life

The Razor's Edge

Till the Clouds Roll By

Night and Day

1948

Key Largo

1949

The Barkleys of Broadway

1950

All About Eve

Halls of Montezuma

1951

Father's Little Dividend

Here Comes the Groom

Quo Vadis 
1952

The Quiet Man

Ivanhoe

1953

Stalag 17

1954

Sabrina

River of No Return

On the Waterfront

Desiree

Rear Window

1955

Guys \& Dolls

Pete Kelly's Blues

1956

Picnic

Around the World in 80 Days

1957

The Bridge on the River Kwai

The Pride and the Passion

1959

The Horse Soldiers

1961

Lover Come Back

1962

To Kill a Mockingbird

Bon Voyage

1963

55 Days at Peking

The Great Escape

It's a Mad, Mad, Mad, Mad World

Tom Jones

1964

The Americanization of Emily

1965

The Sons of Katie Elder

1966

A Man for All Seasons

Wild Angels 
1967

Up the Down Staircase

Thoroughly Modern Millie

You Only Live Twice

1968

Oliver!

Three in the Attic

Chitty Chitty Bang Bang

For Love of Ivy

Finian 's Rainbow

1979

Starting Over

1980

Stir Crazy

1981

Tarzan the Ape Man

1969

Midnight Cowboy

1971

Big Jake

1972

Sounder

The New Centurions

Last Tango in Paris

1973

Magnum Force

1974

The Three Musketeers Herbie Rides Again

1975

Jaws

1976

The Enforcer

The Omen

Taxi Driver

No Deposit, No Return

All the President's Men

Silent Movie

1977

Slap Shot 
Star Wars

Turning Point

1978

Heaven Can Wait

Grease

1983

Sudden Impact

Psycho II

1984

Gremlins

Indiana Jones and the Temple of Doom

Police Academy

Splash

1985

Cocoon

The Jewel of the Nile

Witness

National Lampoon's European Vacation

1986

Heartbreak Ridge

1987

La Bamba

Throw Momma From the Train

Planes, Trains, and Automobiles

1988

Beetlejuice

Die Hard

1989

Parenthood

When Harry Met Sally 